\title{
Pavimento asfáltico contendo escória de ferro-níquel: uma solução viável
}

Analisando as propriedades da escória de FeNi (ferroníquel) a partir do processo de redução e sua viabilidade de utilização na engenharia de pavimentos, como agregado alternativo (miúdo), estudou-se o comportamento de uma mistura asfáltica, utilizando ligante convencional CAP 50/70, agregados naturais e escória de FeNi. Além da análise laboratorial, este estudo contemplou a avaliação e monitoramento de um trecho experimental, localizado em Niquelândia-GO. As amostras foram dosadas pela metodologia Marshall e avaliadas quanto às propriedades de resistência e deformabilidade. A distribuição de partículas de escória de FeNi foram classificadas como areia média e grossa e, de composição química inerte (ABNT - NBR 10004/2004). A mistura contendo FeNi apresentou altos valores de resistência à tração, módulo resiliente e estabilidade, podendo considerar o material uma alternativa promissora no uso em pavimentação de baixo custo, visto que, levou a resultados condizentes com o que as especificações do DNIT recomendam para utilização em pavimentos.

Palavras-chave: Escória; Ferro-níquel; Concreto asfáltico.

\section{Asphalt pavement containing iron-nickel slag: a viable solution}

Analyzing the properties of FeNi slag (ferronickel) from the reduction process and its feasibility of use in pavement engineering, as an alternative aggregate (fine) the behavior of an asphalt mixture was studied, using conventional CAP 50 / 70 binder, natural aggregates and FeNi slag. In addition to laboratory analysis, this study included the evaluation and monitoring of an experimental stretch, located in Niquelândia-GO. The samples were dosed by the Marshall methodology and evaluated for strength and deformability properties. The distribution of FeNi slag particles were classified as medium and coarse sand and inert chemical composition (ABNT - NBR 10004/2004). The mixture containing FeNi presented high values of tensile strength, resilient modulus and stability, being able to consider the material a promising alternative for use in low-cost paving, since it led to results consistent with what the DNIT specifications recommend for use in pavements.

Keywords: Slag; Ferronickel; Concrete asphalt.

Topic: Engenharia da Sustentabilidade e Meio Ambiente

Reviewed anonymously in the process of blind peer.
Received: 17/04/2021

Approved: 18/05/2021
Lisley Madeira Coelho

Instituto Militar de Engenharia, Brasil

madeiralisley@gmail.com

\section{Claudeny Simone Alves Santana}

Instituto Militar de Engenharia, Brasil

cl deny@yahoo.com.br

Antônio Carlos Rodrigues Guimarães Instituto Militar de Engenharia, Brasil cap-guimaraes@hotmail.com
Carmen Dias Castro

Instituto Militar de Engenharia, Brasi

carmendc14@gmail.com

\section{Referencing this:}

COELHO, L. M.; SANTANA, C. S. A.; GUIMARÃES, A. C. R.; CASTRO, C. D.. Pavimento asfáltico contendo escória de ferro-níquel: uma solução viável. Revista Ibero Americana de Ciências Ambientais, v.12, n.5, p.451-461, 2021. DOI: http://doi.org/10.6008/CBPC2179$\underline{6858.2021 .005 .0036}$ 


\section{INTRODUÇÃO}

Nos últimos anos, a atividade de reciclagem de subprodutos tornou-se essencial em relação à necessidade de proteção ambiental. As indústrias de aço e metalurgia, em especial, produzem grandes quantidades de resíduos, referentes aos processos de produção de ferro, aço e outros minérios e metais para a produção de ligas. As duas maiores exploradoras de ferro-níquel são a Anglo American e Votorantim Metais. O Grupo Anglo American está presente no Brasil com a produção de níquel e minério de ferro, negócios que foram integrados em uma estrutura única em 2017. Com as operações de Barro Alto e Codemin, localizadas nas cidades de Barro Alto e Niquelândia (GO), produzem ferroníquel. A produção de ferro-níquel da Anglo-American no $2^{\circ}$ trimestre de 2020 foi de 10.8 mil toneladas (ANLGO AMERIACAN, 2020). Estima-se que aproximadamente 12 a 14 t de escória de níquel sejam produzidos na produção de uma tonelada de liga de níquel (SAHA et al., 2016). O resíduo obtido em larga escala ao final do processo de beneficiamento, fica estocado nos pátios industriais, dando origem a um grande passivo ambiental. Na Figura 1 pode ser observado o depósito de escória de ferroníquel.

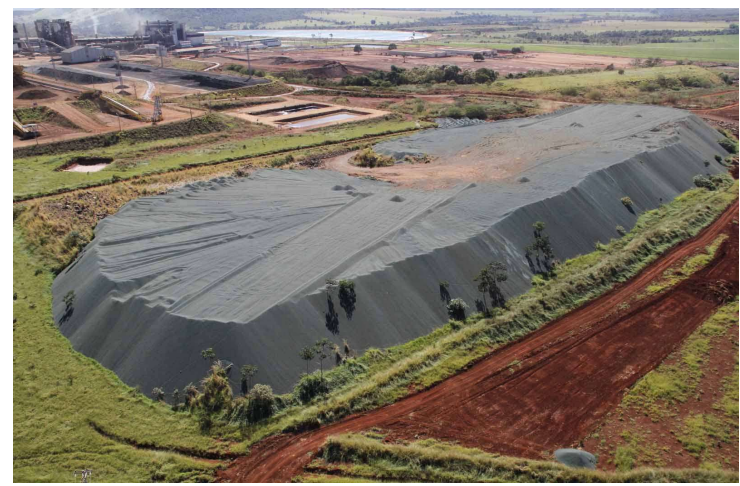

Figura 1: Estoques de escória formados durante os primeiros anos de operação da unidade Barro Alto. Fonte: Santos (2013).

Em razão disso, estabelecer alternativas para o emprego desses resíduos é um dos grandes desafios da sociedade moderna. Na busca de estratégias voltadas para a sustentabilidade, observa-se que muitos destes materiais podem ser utilizados como agregados, em obras de pavimentação asfáltica e na construção civil. Tais estratégias estão relacionadas a inserção do resíduo como componente na produção de telhas cerâmicas, em camadas de pavimentos asfálticos, além de correções do solo, em concreto, cimento e blocos (COSME, 2019; KARLLAS, 2015; INNOCENTINI et al., 2016; SANTOS, 2013; TANGAHU et al., 2015). A escória de ferroníquel, diferentemente das escórias de aciaria e alto-forno, ainda é pouco estudada em termos de aplicação na engenharia civil. Sua caracterização, composição química e mineralógica, quando utilizada como um agregado, exerce grande influência nas tomadas de decisão para o uso ou não deste resíduo.

Nóbrega et al. (2005) citaram alguns casos de contaminação por elementos pesados contidos em tipos de escória distintos, por exemplo um caso em Santo Amaro da Purificação/BA, e um outro em Nova Jersey/EUA. Os elementos químicos presentes no resíduo de escória de FeNi podem oferecer alguns danos ao meio ambiente: escória contendo lixiviado sulfuroso resulta em odor de enxofre e descoloração da água em condições precárias de drenagem (KARAMANOVA, 2011); escória contendo altos níveis de níquel pode 
causar corrosão do ferro e do aço na presença de umidade (NISTOR, 2007). Por esse motivo, a aplicação de escórias ferrosas depende da avaliação de suas características químicas e mineralógicas (ANDREWS et al., 2012; SAMNUR et al., 2016; SAGADIN et al., 2016). No entanto, escórias contendo quantidades desprezíveis de enxofre e níquel não são ecologicamente prejudiciais e, portanto, podem ser utilizadas (FINDANCEVSKA, 2009).

Isso motivou os estudos sobre as características físico-químicas e de lixiviação da escória de ferroníquel, por Demotica et al. (2012), como também o estudo de Andrews et al. (2012) e Samnur et al. (2016), que estudaram sobre as propriedades físico-químicas de escória de ferro-níquel. Por outro lado, outro aspecto que deve ser analisado nas escórias além da contaminação, é a presença de elementos químicos que possam causar a expansibilidade do agregado, como a presença de uma quantidade considerável de óxido de magnésio ( $\mathrm{MgO}$ ) e apenas traços de óxido de cálcio ( $\mathrm{CaO}$ ).

Dentro dessa perspectiva e do potencial de uso, a escória de ferroníquel foi objeto de estudo de diversos autores, nacionais e internacionais, tais como (COSTA, 2019; COSME, 2019; SAMUR et al., 2016; SAGADIN et al., 2016; ANDREWS et al., 2012; DEMOTICA et al., 2012; SANTOS, 2013, CRUZ et al., 2013; WANG et al., 2011; FRANCKLIN JUNIOR et al., 2010; RODRÍGUEZ et al., 2007; LIMA et al., 2009); RICHTER, 2009; NÓBREGA et al., 2005; TASSAVAINEN, 2005; WANG et al., 2004). Como também estudos com registros de utilização de escória de ferro níquel apenas no concreto, conforme Kokubu et al. (1994); Sakoi et al. (2010); Cheol et al. (2015); Dimitrioglou et al. (2015); Saha et al. (2018); Edwin et al. (2019).

Segundo Santos (2013) os novos materiais empregados apresentam características físicas e mecânicas semelhantes às dos agregados convencionais e reflete a importância da integração entre a universidade e a indústria, buscando a viabilidade de novas tecnologias. Nesse contexto, objetivo deste estudo é analisar as propriedades da escória de FeNi (ferro Níquel) a partir do processo de redução uma empresa de mineração localizada no Estado de Goiás, como também verificar a viabilidade de utilização deste resíduo na engenharia de pavimentos, como agregado alternativo (miúdo), dando-lhe um destino sustentável e uma solução eficaz na diminuição do passivo ambiental causado pelo beneficiamento deste resíduo.

\section{METODOLOGIA}

As escórias de FeNi possuem características peculiares em relação à outras obtidas em processos semelhantes em diversas regiões no mundo. Os agregados destas escórias, obtidos através do processo de redução, possuem altos teores de sílica e magnésio, e seu material pertence ao grupo das olivinas, constituídas por silicatos de magnésio e ferro. A olivina apresenta-se, geralmente, com coloração verde oliva, caracterizada pela sua composição química.

A composição química e a estrutura física das escórias podem variar de acordo com a eficiência de operação do forno, do teor de minérios utilizados e do método de resfriamento (MASUERO, 1998). A escória de ferro-níquel é produzida na fusão do minério de níquel em forno elétrico, onde elementos não metálicos, tais como SiO2, MgO e Fe2O3, são granulados na presença de água. Neste processo, são geradas 
grande quantidade de escória (ANGLO AMERICAN, 2012). Tanto no processo de redução, quanto no refino do ferroníquel, são geradas as escórias, sendo que no objeto deste estudo é a utilização da escória do processo da redução. Nesse sentido, a Tabela 1 apresenta a composição química média da escória de ferroníquel.

Tabela 1: Composição química média da escória de ferroníquel.

\begin{tabular}{|l|c|c|c|c|}
\hline & $\mathrm{Ni}(\%)$ & $\mathrm{Fe}(\%)$ & $\mathrm{SiO} 2(\%)$ & $\mathrm{MgO}(\%)$ \\
\hline Rejeito: Escória de redução & 0,12 & 11,85 & 51,45 & 28,84 \\
\hline
\end{tabular}

Fonte: Santos (2013).

Como já mencionado, uma quantidade considerável de minério é utilizada anualmente neste processo metalúrgico, que compreende as fases de sua preparação (esmagamento, homogeneização e secagem): calcinação, redução e refino. Na redução obtém-se o FeNi, que, depois, é enviada à refinação, a fim de remover as impurezas, tais como o enxofre e fósforo. Após esta fase, a liga é adequada para a comercialização.

Amostras de escória de ferroníquel foram coletadas na unidade Codemin, operação da Anglo American em Niquelândia-GO. As amostras foram analisadas quimicamente e ambientalmente pela própria Codemin e seus resultados foram fornecidos para essa pesquisa. Os agregados virgens a serem utilizados, foram fornecidos pela empresa ONA e se tratavam de calcários britados subdivididos nas seguintes frações: brita 1 , brita 0 e pó pedrisco. Da mesma forma que os agregados naturais, o ligante asfáltico tipo CAP 50/70, foi fornecido pela empresa ONA, e conduzido ao Laboratório de Ligantes e Misturas Betuminosas do IME no Rio de Janeiro para a realização dos ensaios de caracterização física tradicional, apresentados na Tabela 2 e 3.

Tabela 2: Caracterização física dos agregados.

\begin{tabular}{|l|l|}
\hline Ensaio & Norma \\
\hline Densidade Real & DNER-ME 084/95 \\
\hline Densidade Aparente & DNER-ME 117/94 \\
\hline Absorção & DNER-ME 195/97 \\
\hline Abrasão Los Angeles & DNER-ME 035/94 \\
\hline Impacto Tétron & DNER-ME 399/99 \\
\hline Adesividade & DNER-ME 078/94 \\
\hline
\end{tabular}

Tabela 3: Caracterização física do ligante asfáltico.

\begin{tabular}{|c|c|}
\hline Ensaio - CAP 50/70 & Norma \\
\hline Penetração (100g, 5s, 25ㅇ, 0,1mm) & DNIT 155/2010 - ME \\
\hline Ponto de Amolecimento, min. & DNIT 131/2010 - ME \\
\hline Viscosidade Brookfiel a 135으, SP 21, 20 rpm, mín & ASTM D 4402 /2007 \\
\hline Viscosidade Brookfiel a 150C, SP 21, mín. & ASTM D $4402 / 2007$ \\
\hline Viscosidade Brookfiel a 177으, SP 21 & ASTM D $4402 / 2007$ \\
\hline Ponto de fulgor, mín. & DNER-ME $148 / 1994$ \\
\hline Dutilidade a 25으, mín & DNIT-ME $130 / 2010$ \\
\hline Efeito do calor e do ar (RTFOT) a 163으, $85 \mathrm{~min}$ & ASTM D2872 / 1999 \\
\hline Aumento do ponto de amolecimento, máx. & DNIT 131/2010 - ME \\
\hline Penetração retida, mín. & DNIT 155/2010 - ME \\
\hline Ductilidade a $25^{\circ} \mathrm{C}$, mín. & DNIT-ME $130 / 2010$ \\
\hline Densidade Relativa & \\
\hline
\end{tabular}

A dosagem seguiu a metodologia Marshall, prescrita pelo DNER-ME 043/95. Para a escolha do traço para o trecho experimental do pátio de estacionamento, localizado em Niquelândia-GO, foi realizado o 
enquadramento dos agregados pelo método das tentativas na curva de granulometria, exibida na Figura 2. Dessa maneira, observou-se que a granulometria da mistura utilizada neste ensaio se encaixa na Faixa C do DNIT-ES 031/06, obedecendo aos limites inferiores e superiores da curva de granulometria preconizados pela norma.

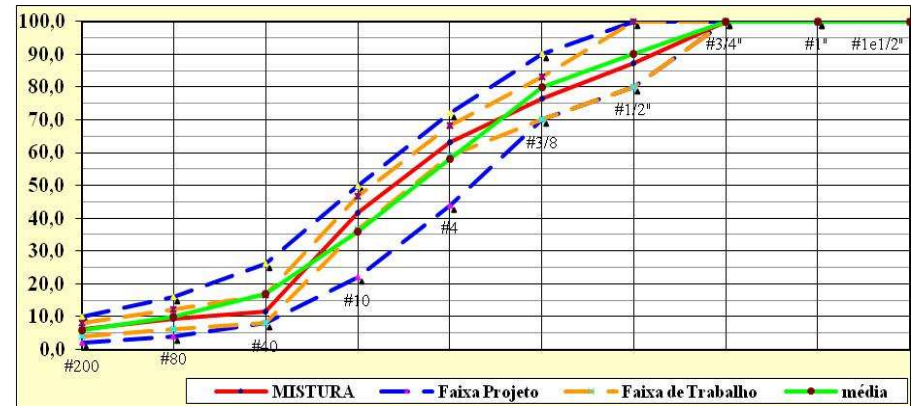

Figura 2: Curva granulométrica da mistura.

Foi analisada a propriedade de resistência das misturas por meio dos ensaios de Resistência à Tração por Compressão Diametral (RT), de acordo com a norma DNIT-ME 136/2010. A deformabilidade foi avaliada com base nos ensaios de Módulo de Resiliência (MR), conforme prescrições da norma DNIT-ME $135 / 2010$.

Para a realização do trecho experimental e análise do comportamento de uma mistura asfáltica contendo escória de FeNi, foi utilizado neste artigo a escória de FeNi obtida pelo processo de redução das duas unidades industriais que pertencem à empresa Anglo-Americana, localizada em Goiás, Brasil. Logo após a coleta de todos os materiais envolvidos na pesquisa, estes foram levados para o Laboratório de Ligantes e Misturas Betuminosas e Laboratório de Solos do Instituto Militar de Engenharia.

Os solos coletados foram caracterizados para que se definisse se haveria necessidade de melhoramento do suporte. Foi realizado a caracterização tecnológica tradicional dos agregados para composição asfáltica, de revestimento do tipo concreto asfáltico à quente, utilizando a metodologia de dosagem marshall. Em seguida, partiu-se para a construção do estacionamento, onde o processo construtivo foi executado em 03 dias. Durante a fase de usinagem pôde-se verificar a diferença de granulometria da mistura resultante, pois os agregados coletados na região da execução da obra eram diferentes daqueles fornecidos para a dosagem em laboratório. Além disso, durante o processo de execução a empresa responsável pela obra aumentou em 0,5 pontos porcentuais o teor de ligante de projeto, fato que gerou alteração no traço final executado, o que ocasionou pequenas desagregações em alguns pontos do revestimento.

\section{RESULTADOS E DISCUSSÃO}

O solo coletado da camada de base foi classificado por meio da metodologia MCT (método das pastilhas), desenvolvida por Nogami et al. (1994), como laterítico argiloso, de plasticidade baixa, contração alta (CA - $\Delta \emptyset>1,0 \mathrm{~mm}$ ), consistência dura, sem trincas e sem inchamento. A granulometria lavada do solo, apresentou $30 \%$ de material retido na peneira de no 4, evidenciando expressiva presença de material pedregulhoso. 
Os resultados dos ensaios, para determinação da massa específica aparente seca máxima, umidade ótima e Índice de Suporte Califórnia do solo, podem ser visualizados na Tabela 4. De acordo com os resultados encontrados, optou-se em substituir 30\% do solo da camada de base por escória de ferro níquel, resultando em um incremento da densificação da camada de base em torno de $22 \%$, bem como do seu suporte (acréscimo de cerca de $10 \%$ no valor de CBR) e em uma diminuição do percentual de umidade ótima em $61,8 \%$, devido à baixa absorção e presença de ferro na escória de ferro níquel.

Tabela 4: Resultados dos ensaios de compactação e CBR.

\begin{tabular}{|l|l|l|l|}
\hline Amostra & MEASM $\left.\mathbf{( k g} / \mathbf{m}^{\mathbf{3}}\right)$ & Umidade Ótima (\%) & CBR (\%) \\
\hline Solo (camada de base) & 1795 & 21,2 & 70 \\
\hline Solo + 30\% de escória de FeNi & 2195 & 8,1 & 80,4 \\
\hline
\end{tabular}

Em relação ao resíduo de escória de FeNi, segundo a norma ABNT NBR 10004 (2004), podem ser classificados em três classes: classe I (perigosos), classe II (não inertes), e classe III (inertes). Neste contexto, as análises da escória de FeNi de redução apresentou em sua composição teores relevantes de metais tóxico-perigosos, como o níquel, cromo, cobre e vanádio, o que levou à classificação tipo classe III - inertes, pois nenhum dos constituintes apresentou concentração acima dos valores estabelecidos na ABNT NBR 10004 (2004).

De acordo com Santana et al. (2014), pôde-se considerar que os metais se encontram na forma não passível de lixiviação e solubilização, não trazendo assim, nenhum risco relativo à contaminação ao ambiente que irá compor. Os ensaios de caracterização dos agregados foram executados segundo metodologia normatizada pelo Departamento Nacional de Infraestrutura de Transporte e estão dispostos na Tabela 5.

Tabela 5: Caracterização física dos agregados.

\begin{tabular}{|l|l|l|l|l|l|l|l|}
\hline Ensaio & Brita 1 & Brita 0 & Pedrisco & Escória FeNi & Cimento & Limites & Norma \\
\hline Densidade Real & 2,82 & 2,88 & 2,85 & 3,03 & 3,1 & & DNER-ME 084/95 \\
\hline Densidade Aparente & 2,79 & 2,75 & - & 2,99 & 1,12 & & DNER-ME 117/94 \\
\hline Absorção & $1,70 \%$ & - & - & $0,10 \%$ & - & $\leq 2$ & DNER-ME 195/97 \\
\hline Abrasão Los Angeles & $25,60 \%$ & - & - & - & - & $\leq 65$ & DNER-ME 035/94 \\
\hline Impacto Tétron & $30,61 \%$ & - & - & - & - & $\leq 12$ & DNER-ME 399/99 \\
\hline Adesividade & Satisfatória & Satisfatória & - & - & - & & DNER-ME 078/94 \\
\hline
\end{tabular}

Observa-se através da tabela 5, que o resultado para o ensaio de absorção da Brita 1 mostrou-se um pouco elevada, porém encontra-se dentro dos limites preconizados pela norma, tendo sido a absorção do agregado de calcário menor que 2\%, conforme DNER-ME 195/97, e adesividade satisfatória. A baixa absorção da escória (igual a 0,1\%), é devido à ausência de poros na escória de ferro níquel, como foi observado através de sua aparência vítrea pelo ensaio de microscopia eletrônica de varredura (MEV). Este foi um fator preponderante, pois favoreceu o baixo consumo de ligante.

A perda de massa do material pelo ensaio de Abrasão Los Angeles foi igual a 25,6\%. Tal qual o resultado do ensaio de perda ao choque no aparelho Tréton igual a 30,61\%, que foi menor que $60 \%$ conforme limite estabelecido pela norma DNER-ME 399/99. Os valores de densidade da escória de ferro níquel mostrados na Tabela 5 aproximadamente de $6 \%$ a $8 \%$ maiores ao comparar com os dos agregados 
comuns. Este fato se deve principalmente pela presença do ferro, que é encontrado em sua composição química. Balbo (2007) e Silva (2010) também atribuíram o elevado valor da densidade da escória à composição do ferro no agregado. Na Tabela 6 encontram-se os resultados da caracterização física do ligante asfáltico CAP 50/70 utilizados no traço estudado.

Tabela 6: Ensaios de controle do Cimento Asfáltico de Petróleo - CAP 50/70

\begin{tabular}{|c|c|c|c|}
\hline Ensaio - CAP 50/70 & Unidades & Limites & Resultados \\
\hline Penetração $(100 \mathrm{~g}, 5 \mathrm{~s}, 25 \circ \mathrm{C}, 0,1 \mathrm{~mm})$ & $0,1 \mathrm{~mm}$ & 50 a 70 & 50 \\
\hline Ponto de Amolecimento, min. & oC & 52 & 58,6 \\
\hline Viscosidade Brookfiel a 135ㄷ, SP 21, 20 rpm, mín & & 274 & 375 \\
\hline Viscosidade Brookfiel a 150C, SP 21, mín. & $\mathrm{Cp}$ & 112 & 183 \\
\hline Viscosidade Brookfiel a 177으, SP 21 & & 57 a 285 & 68 \\
\hline Ponto de fulgor, mín. & $\stackrel{\circ}{\circ}$ & 235 & 348 \\
\hline Dutilidade a 25으, mín & $\mathrm{cm}$ & 60 & $>100$ \\
\hline Aumento do ponto de amolecimento, máx. & $\stackrel{\circ}{\circ}$ & 8 & 65,5 \\
\hline Penetração retida, mín. & $\%$ & 55 & 55 \\
\hline Ductilidade a $25^{\circ} \mathrm{C}$, mín. & $\mathrm{cm}$ & 20 & $>100$ \\
\hline Densidade Relativa & & & 1,04 \\
\hline
\end{tabular}

Os resultados de caracterização do ligante foram satisfatórios e obedeceram aos limites estabelecidos pelas normas. Como já foi mencionado, através do método das tentativas, obteve-se uma mistura teórica adequada à faixa " $C$ " do DNIT, segundo ES 031/2006, para composição da massa asfáltica do tipo CAQ. A Tabela 7 apresenta uma comparação de uma composição convencional de massa asfáltica utilizada na restauração da GO-532, que dá acesso a entrada da mineradora produtora da escória de ferro níquel, com a composição apresentada nesta pesquisa. A adição de melhorador de adesividade (DOPE) foi necessária para os dois casos, pois as britas se tratavam de granito que possuíam poucos poros, e a escória por ter baixa absorção (igual a 0,1\%).

Tabela 7: Comparação entre composições asfálticas, convencional e com $40 \%$ de escória de FeNi.

\begin{tabular}{|l|l|}
\hline Trecho Convencional GO-532 & Trecho com $\mathbf{4 0 \%}$ de escória de FeNi \\
\hline Brita $0=35 \%$ & Brita $0=15 \%$ \\
\hline Brita $1=20 \%$ & Brita $1=22 \%$ \\
\hline Pedrisco $=22 \%$ & Pedrisco $=20 \%$ \\
\hline Areia $=20 \%$ & Escória $=40 \%$ \\
\hline Cimento CPII 32=3\% & Cimento CPII $32=3 \%$ \\
\hline CAPE $50 / 70=4,10 \%$ & CAPE $50 / 70=4,55 \%$ \\
\hline DOPE $=0,3 \%$ & DOPE $=0,3 \%$ \\
\hline
\end{tabular}

De acordo com a Tabela 7, a composição encontrada para $40 \%$ de consumo de escória de ferro níquel apresentou uma diminuição considerável no consumo de brita 0 , cerca de $43 \%$, e a exclusão total do consumo de areia, pois a granulometria da escória de FeNi, pelos valores obtidos, pode ser considerada por suas frações passantes um agregado miúdo do tipo areia média à grossa. O consumo de ligante houve um aumento discreto, mas sem muito impacto econômico, enquanto o melhorador de adesividade e de cimento não foram alterados. Estes dados demonstram a viabilidade econômica do resíduo, por poder ser adquirido por um valor de baixo custo e por diminuir o consumo de agregados pétreos, que são os mais onerosos no caso de CAQ. Essa quantidade expressiva de consumo percentual de escória, quando se trata em dar um destino sustentável para um resíduo, é bastante promissora.

Dando-se continuidade aos resultados obtidos, a Tabela 8 apresenta os resultados obtidos através 
da metodologia Marshall para o teor ótimo de ligante, obtido através da análise e confecção dos corpos de prova de CAQ nos teores de 3,5\%, 4,5\% e 5,5\% de ligante asfáltico do tipo CAP 50/70.

Tabela 8: Resultados obtidos pela metodologia Marshall

\begin{tabular}{|l|c|l|}
\hline Determinações & Resultados & ES 031/2006 DNIT \\
\hline Teor de Ligante (\%) & 4,55 & - \\
\hline Densidade Aparente & 2,5 & - \\
\hline Volume de Vazios (\%) & 3,5 & $3-5$ \\
\hline Volume de Agregado Mineral (\%) & 15,5 & - \\
\hline Relação Betume - Vazio (\%) & 77 & $75-82$ \\
\hline Densidade máxima teórica & 2,52 & - \\
\hline Estabilidade (Kgf) & 850 & $>500$ \\
\hline Resistência à tração por compressão diametral estática (MPa) & 0,72 & $>0,65$ \\
\hline
\end{tabular}

Os resultados apresentados na Tabela 8 estão de acordo com o que a especificação ES 031/2006 DNIT. O volume de vazios atingiu quase o limite inferior, demonstrando que a massa asfáltica após compactação se tornou bastante densa, com poucos vazios. Apresentam-se na Tabela 10 os resultados médios obtidos do ensaio de módulo resiliente, segundo a norma ABNT NBR 16018 (2011), em três corpos de prova moldados: em campo no momento da execução do revestimento asfáltico com o teor ótimo encontrado (4,55\%) em laboratório, e calibrado na usina que confeccionou a massa de CAQ. O resultado médio total foi de $6323 \mathrm{MPa}$, que é um valor expressivo e satisfatório tendo por base os conceitos básicos da mecânica dos pavimentos. Neste sentido, o trincamento do revestimento asfáltico, causado pela deformação resiliente das camadas subjacentes, pode ser atenuado devido ao valor encontrado.

Tabela 10: Resultados de módulo resiliente.

\begin{tabular}{|l|l|}
\hline Corpos de prova & MR (MPa) \\
\hline 1 & 5564 \\
\hline 2 & 6192 \\
\hline 3 & 7214 \\
\hline Média & 6323 \\
\hline
\end{tabular}

Dando continuidade ao controle tecnológico da mistura, no ensaio de extração do ligante, para a verificação do teor ótimo, observou-se um pequeno acréscimo no teor ótimo de ligante $(0,66 \%)$, que foi considerado dentro de um limite aceitável, devido às calibrações da usina de asfalto. Os agregados permaneceram na faixa " $C$ " do DNIT, com algumas variações, porém dentro da faixa de trabalho e tolerâncias permitidas para cada peneira.

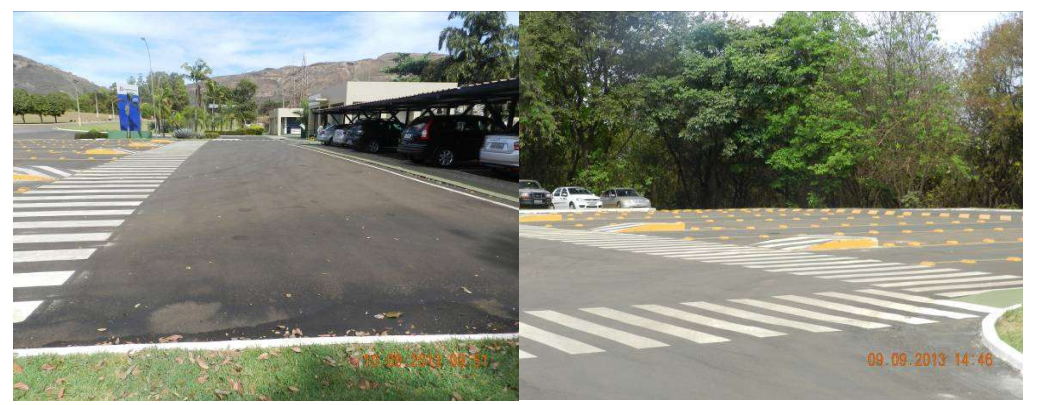

Figura 3: Estacionamento para embarque e desembarque de passageiros concluído.

A partir dos ensaios em laboratório, foi possível no ano de 2013 a execução de um pequeno trecho experimental para pavimentação do estacionamento dos ônibus que transportam os funcionários da 
empresa Codemim, na cidade de Niquelândia-Go, região central do Brasil e distante cerca de 3 horas da capital Brasília. A Figura 3 apresenta o estacionamento para embarque e desembarque de passageiros, após a execução de todas as etapas listadas neste trabalho.

Devido à alteração no teor de ligante de projeto durante a usinagem da mistura, e consequentemente alteração no traço final utilizado, ocasionou em pequenas desagregações em alguns pontos do revestimento, conforme observado na Figura 4. Porém, esta desagregação foi estabilizada após alguns meses de operação e o estado do pavimento após quatro anos de operação pode ser considerado como satisfatório e em boas condições de uso, conforme verificado nas Figuras 5 a 7.

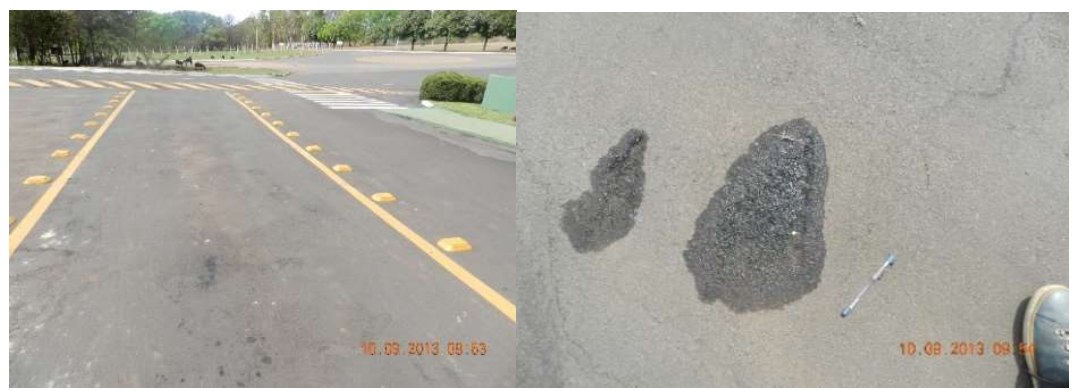

Figura 4: Desagregação no pavimento executado

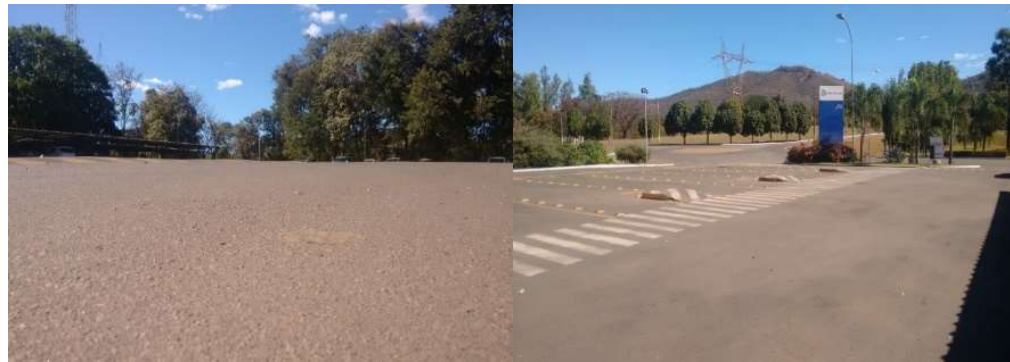

Figura 5: Vista do pavimento após quatro anos de execução.

\section{CONCLUSÕES}

Este trabalho contemplou o estudo experimental da adição de escória de ferro níquel na camada de base e na massa asfáltica de revestimento de um estacionamento para embarque e desembarque de passageiros. Segundo as análises feitas, pôde-se chegar às seguintes conclusões: A escória de ferro níquel, por ter tido baixas concentrações de elementos nocivos ao meio ambiente, foi considerada inerte, sendo possível usar em pavimentos sem que ocorra contaminação do solo ou água; Na camada de base, o solo utilizado foi classificado como laterítico argiloso, com cerca de 30\% de pedregulho; com a adição de $30 \%$ de escória, observou-se no acréscimo de $10 \%$ no valor de CBR, além do aumento do seu valor de massa específica seca máxima e diminuição do seu teor de umidade ótima; Quanto à massa asfáltica tipo CAQ para revestimento do estacionamento, com a adição de $40 \%$ de escória de ferro níquel em substituição da areia, obtiveram-se resultados em acordo com o exigido pela DNIT ES 031/2006; No momento da execução do trecho experimental, após passar por todas as etapas do processo construtivo, verificou-se que o teor de CAP 50/70 atingiu um valor de apenas $0,66 \%$ a mais que o teor teórico obtido em laboratório e que as faixas granulométricas dos agregados aplicados na mistura foram atendidas e se enquadraram dentro da faixa "c" do DNIT (2004); O valor de médio do módulo resiliente do CAQ foi de $6323 \mathrm{MPa}$, indicando a 
eficiência do revestimento quanto aos parâmetros da mecânica dos pavimentos. Considerando os bons resultados obtidos nesta pesquisa, concluiu-se que a escória de ferro níquel pode ser usada em camadas de infraestrutura, pois houve incremento dos seus valores mecânicos, visto que, levou a resultados condizentes com o que as especificações do DNIT recomendam para utilização em pavimentos.

\section{REFERÊNCIAS}

ANGLO AMECICAN. Relatório de produção da Anglo American plc para o segundo trimestre, 2020.

ASTM. American Society for Testing and Materials. Standard Test Method for Effect of Heat and Air on a Moving Film of Asphalt (Rolling Thin-Film Oven Test) D2872, 1999.

ASTM. American Society for Testing and Materials. Standard test method for viscosity determination of asphalt at elevated temperatures using a rotational viscometer, 2007.

ABNT. Associação Brasileira de Normas Técnicas. NBR 10004. Resíduos Sólidos-Classificação, 2004.

ABNT. Associação Brasileira de Normas Técnicas. NBR 16018. Misturas asfálticas - Determinação da rigidez por compressão diametral sob carga repetida, 2011.

ANDREWS, A.; GIKUNOO, E.; OFUSU-MENSAH, L.; TOFAH, H.; BANSAH, S.. Chemical and Mineralogical Characterization of Ghanaian Foundry Slags. Journal of Minerals \& Materials Characterization \& Engineering, v.11, n.2 p.183-192, 2012.

BALBO, J. T.. Pavimentação asfáltica: materiais, projeto e restauração. Oficina de Textos, 2007.

COSME, J.. Utilização de escória de ferroníquel na composição de concreto betuminoso usinado à quente. Dissertação (Mestrado em Geotecnia) - Universidade Federal de Ouro Preto, Ouro Preto, 2019.

COSTA, J. P. R.. Caracterização da escória de ferro-níquel para aplicação como enrocamento de diques galgáveis drenantes. Dissertação (Mestrado em Geotecnia)Universidade Federal de Ouro Preto, Ouro Preto, 2019.

CRUZ, Y.R; ROJAS-PURÓN, A.L; PONS HERRERA, J. A. Caracterización físico-química y mineralógica de la escoria de fundición de ferroníquel de Moa. Minería y Geología, v.29 n.4, p. 13-28, 2013.

CHOI, Y.C., CHOI, S.. Alkali-silica reactivity of cementitious materials using ferronickel slag fine aggregates produced in different cooling conditions. Cons. Build. Mater, v.99, 279287, 2015.

DEMOTICA, J. S.; AMPARADO, R. F.; MALALUAN, R. M.; DEMAYO, C. G.. Characterization and Leaching Assessment of Ferronickel Slag from a Smelting Plant in Iligan City, Philippines. International Journal of Environmental Science and Development, v.3, n.5, 2012.

DIMITRIOGLOU, N.; TSAKIRIDIS, P. E.; KATSIOTIS, N. S.; KATSIOTIS, M. S.; PERDIKIS, P.; BEAZI, M.. Production and characterization of concrete paving blocks containing ferronickel slag as a substitute for aggregates. Waste and Biomass Valorization, 2015.
DNER. Departamento Nacional de Estradas de Rodagem. ME 078, agregado: adesividade a ligante betuminoso, 1994.

DNER. Departamento Nacional de Estradas de Rodagem. ME 078, agregado: adesividade a ligante betuminoso, 1995.

DNER. Departamento Nacional de Estradas de Rodagem.ME 117, Mistura Betuminosa: determinação da densidade aparente, 1994.

DNER. Departamento Nacional de Estradas de Rodagem. ME 195, Agregados: determinação da absorção e da massa específica de agregado graúdo,1997.

DNER. Departamento Nacional de Estradas de Rodagem. ME 035, Agregados: determinação da abrasão los angeles,1998.

DNER - Departamento Nacional de Estradas de Rodagem. ME 148, Agregados: determinação do ponto de fulgor e de combustão,1994.

DNER. Departamento Nacional de Estradas de Rodagem. ME 399, Agregados: determinação da perda ao choque no aparelho tréton, 1999.

DNIT. Departamento Nacional de Infra-estrutura de Transportes. DNIT 031/2006 - ES Pavimentos flexíveis: Concreto Asfáltico - Especificações de serviço, 2004.

DNIT. Departamento Nacional de Infraestrutura de Transporte. ME 135, Pavimentação Asfáltica: Misturas Asfálticas - Determinação do Módulo de Resiliência Método de Ensaio, 2010.

DNIT. Departamento Nacional de Infraestrutura de Transporte. ME 136: determinação da resistência à tração por compressão diametral - método de ensaio, 2010.

DNIT. Departamento Nacional de Infraestrutura de Transporte. ME 155, Material asfáltico: determinação da penetração - Método de ensaio, 2010.

DNIT. Departamento Nacional de Infraestrutura de Transporte. ME 131, Materiais asfálticos: determinação do ponto de amolecimento - Método do Anel e Bola -Método de ensaio, 2010.

DNIT. Departamento Nacional de Infraestrutura de Transporte. ME 130: Recuperação elástica de materiais asfálticos pelo ductilômetro: método de ensaio. Brasília: DNIT, 2010.

FIDANCEVSKA, E.; VASSILEV, V.; HRISTOVA-VASILEVA, T.; MILOSEVSKI, M.. On possibilidade de aplicação de resíduos industriais de escória metalúrgica e vidro de TV, Conheceu, v.44, n.2, p.189-196, 2009.

FRANCKLIN JUNIOR, I.; ALMEIDA, F. A. S.. Verificação das 
propriedades de concretos produzidos com agregados de escória de níquel provenientes de mineração do município de Pratápolis-MG. CONGRESSO BRASILEIRO DE CONCRETO IBRACON, 52. Anais, 2010.

INNOCENTINI, M. D. M.; KALLAS, F. P. E.; MONTEDO, O. R. K. Utilização da Escóriagerada na produção de níquel como matéria-prima para produção de telhas cerâmicas. In: CONGRESSO BRASILEIRO DE CERÂMICA, 60. Anais. Águas de Lindóia, 2016.

KARAMANOVA, E.; AVDEEV, G.; KARAMANOV, A.. Cerâmica de escória de alto forno, caulino e quartzo, J. Euro. Ceram. Soc., v.31, p.989-998, 2011.

KARLLAS, F. P. E.. Valorização da escória gerada na produção de níquel como matéria prima para produção de telhas cerâmicas. Dissertação (Mestrado em Tecnologia Ambiental) - Universidade de Ribeirão Preto, Riberirão Preto, 2015.

KOKUBU, K.; SHOYA, M.. Guidelines for construction using ferronickel slag fine aggregate concrete. Concrete Library, n.78, 1994.

LIMA, R. L.; ZAMPIERON, J. V.. Avaliação da escória de níquel como possível matéria prima para pigmento cerâmico. Ciência et Praxis, v.2, n.4, 2009.

NISTOR, L.; CIOROI, M.. Possibilidades de reciclagem de escória metalúrgica, 2007.

NOGAMI, J. S.; VILLIBOR, D. F.. “Identificação expedita dos grupos da classificação MCT para solos tropicais. In: CONGRESSO BRASILEIRO DE MECÂNICA DOS SOLOS E ENGENHARIA DE FUNDAÇÕES, 10. Anais. Foz do Iguaçu, 1994.

MASUERO, A. B.. Estabilização das escórias de aciaria elétricas com vistas a sua utilização como material para construção civil. Tese (Doutorado em Engenharia de Minas, Metalúrgica e de Materiais) - Universidade Federal do Rio Grande do Sul, 2001.

NÓBREGA, L. M.; ROSA, N. M. G. S.; CAMPOS, L. E. P.; SOARES, J. B.. Avaliação Ambiental de Escória de Ferroliga Aplicada em Revestimentos de Pavimentos em Salvador. REUNIÃO ANUAL DE PAVIMENTAÇÃO. Anais. Curitiba: 2005.

RICHTER, D.. Uma rota de recuperação de metal a partir de escória secundária da produção de ferroniquel. Dissertação (Mestrado em Engenharia de Minas e de Petróleo) Universidade de São Paulo, São Paulo, 2009.

ROdRíGUEZ, H. A. P.; VILLAMIL, F. R. P.. Estudio de las fases predominantes y caracterización de las escórias del processo de obtención de ferro níquel. Scientia et Technica,v.13, n.36, 2007.
SAGADIN, C.; LUIDOLD, S.; WAGNER, C.; WENZL, C.. Melting Behaviour of Ferronickel Slags. The Minerals, Metals \& Materials Society, v.68, n.12, 2016.

SAHA, A. K.; SARKER, P. K.. Expansion due to alkali-silica reaction of ferronickel slag fine aggregate in OPC and blended cement mortars. Cons. Build. Mater., v.123, p.135142,2016

SAMNUR, S.; HUSAIN, H.; ZULFI, A.; SUJIONO, E. H.. Study on physical-chemical properties of furnace-nickel-slag powder for geopolymer application. Jurnal Pendidikan Fisika Indonesia, v.12, n.2, p.177-182, 2016.

SANTANA, C. S. A.; SANTOS, G. P. P.; GONDIM, R. C.; GUIMARÃES, A. C. R.; CARNEIRO, L. A. V.. Avaliação das propriedades de concreto de alta resistência com agregados miúdos de escória de ferro níquel. 2014.

SANTOS, G. P. P.; GUIMARÃES, A. C. R.; CARNEIRO, L. A. V.; SANTANA, C. S. A.. Use of Ferronickel Slag for Paving. Ninth International Conference on the Bearing Capacity of Roads, Railways and Airfields, 2013.

SAKOI, Y.; ABA, M.; TSUKINAGA, Y.; NAGATAKI, S.. Properties of Concrete used in Ferronickel Slag Aggregate. Proceedings of the 3rd International Conference on Sustainable Construction Materials and Technologies, Tokyo, 2013.

SILVA, R. G. O.. Estudo laboratorial do desempenho mecânico de misturas asfálticascom resíduos industriais de minério de ferro. Dissertação (Mestrado em Geotecnia ) Universidade Federal de Ouro Preto, OuroPreto, 2010.

TANGAHU, B. V.; WARMADEWANTHI, I.; SAPTARINI, D.; PUDJIASTUTI, L.; TARDAN, M. A. M.; LUQMAN, A.. Ferronickel Slag Performance from Reclamation Area in Pomalaa, Southeast Sulawesi, Indonesia. Advances in Chemical Engineering and Science, v.5, p.408-412. http://dx.doi.org/10.4236/aces.2015.53041, 2015.

TOSSAVAINEN, M.. Leaching Results in the Assessment of Slag and Rock Materials as Construction Material. Doctoral Thesis. Luleå University of Technology Department of Chemical Engineering and Geosciences Division of Mineral Processing, 2005.

WANG, G.; EMERY, J.. Technology of slag utilization in highway construction. John Emery Geotechnical Engineering Limited, Toronto, Ontario, Canada. In: ANNUAL CONFERENCE TRANSPORTATION ASSOCIATION OF CANADA QUÉBEC CITY. Proceedings. Québec: 2004.

WANG, G.. Hot-mix asphalt that contains nickel slag aggregate: laboratory evaluation of use in highway construction. Journal of the Transportation Research Board., 2011.

A CBPC - Companhia Brasileira de Produção Científica (CNPJ: 11.221.422/0001-03) detém os direitos materiais desta publicação. Os direitos referem-se à publicação do trabalho em qualquer parte do mundo, incluindo os direitos às renovacões, expansões e disseminacõos da contribuicão, bem como outros direitos subsidiários. Todos os trabalhos publicados eletronicamente poderão posteriormente ser publicados em coletâneas impressas sob coordenacão da Sustenere Publishing da Companhia Brasileira de Produção Científica e seus parceiros autorizados. Os (as) autores (as) preservam os direitos autorais, mas não têm permissão para a publicação da contribuição em outro meio, impresso ou digital, em português ou em tradução. 